Ensino, Saúde e Ambiente - V7 (3), p. 50-69, Dez. 2014

\title{
AS POTENCIALIDADES DA UTILIZAÇÃO DE UM BLOG COMO FERRAMENTA PARA ORGANIZAÇÃO DE ATIVIDADES DE PROMOÇÃO DA SAÚDE NAS AULAS DE EDUCAÇÃO FÍSICA
}

\section{THE POTENTIAL USE OF A BLOG AS A TOOL FOR ORGANIZATION OF ACTIVITIES OF HEALTH PROMOTION IN PHYSICAL EDUCATION CLASSES}

\author{
Claudia Toillier Leotty ${ }^{1}$, Julio Cesar Bresolin Marinho \\ Curso de Especialização em Mídias na Educação-Universidade Federal de Pelotas \\ (UFPel) \\ 1claudia-toillier@hotmail.com; ${ }^{2}$ marinhojcb@gmail.com
}

\section{RESUMO}

Este artigo tem como objetivo analisar as mídias com suas contribuições para a promoção da saúde na escola, através das aulas de Educação Física. Percebemos que as mídias estão constantemente chamando a atenção, orientando, indicando soluções e trazendo informações. Com isso, percebemos a necessidade de uma constante interação entre os meios tecnológicos midiáticos e as atividades físicas, responsáveis pelo desenvolvimento motor e psicológico do nosso aluno. Na presente pesquisa, de caráter qualitativo, analisamos um blog e suas potencialidades como ferramenta para consultas, estudos, análises e organização das aulas de Educação Física, contribuindo para a promoção da saúde dos adolescentes. A partir das análises realizadas sobre as postagens do blog, compreendemos que esta ferramenta interativa pode servir de apoio para elaboração de aulas mais dinâmicas e significativas. Evidenciamos também, que além de constituir-se como um potente espaço pedagógico, o blog permite: a construção interativa de novos conhecimentos, o compartilhamento de ideias e, a análise crítica do conteúdo das postagens. Através de vídeos, textos, pesquisas, fotos, definições, doenças associadas e suas consequências, bem como alternativas para os problemas enfrentados, postados no blog analisado, acabam por possibilitar o enriquecimento da prática educativa do professor de Educação Física.

Palavras-chave: Promoção da saúde, mídias, blog, Educação Física.

\begin{abstract}
This article aims to analyze the media for their contributions to health promotion at school through Physical Education classes. We realize that the media are constantly calling attention, guiding, indicating solutions and providing information. With this, we realize the need for a constant interaction between the media and technological means physical activities, responsible for motor and mental development of our students. In this research, qualitative, we analyze a blog and its potential as a tool for consultations, studies, analysis and organization of Physical Education classes, contributing to the promotion of adolescent health. From the analyzes performed on blog posts, we understand that this interactive tool can serve to support development of more dynamic and meaningful lessons. We show also that in addition to being as a powerful pedagogical space, the blog allows: interactive construction of new knowledge, sharing of ideas and critical analysis of the content of the posts. Through videos, texts, searches, photos, settings, associated diseases and their consequences, as well as alternatives to the problems faced, posted on the blog analyzed, ultimately enabling the enrichment of the educational practice of Physical Education teacher.
\end{abstract}

Key words: Health promotion, media, blog, Physical Education. 


\section{INTRODUÇÃO}

$\mathrm{O}$ artigo que apresentamos aqui refere-se a um trabalho de conclusão do Curso de Especialização em Mídias na Educação, o qual foi aliado a nossa atuação e vivências profissionais - ministrar aulas de Educação Física. A escolha pela realização dessa investigação emerge pela análise do perfil dos alunos que frequentam as escolas hoje sujeitos que estão na sociedade da informação, cercado delas por todos os lados. Com isso, começamos a nos interessar por investigar o "sofisticado" leque de opções metodológicas disponíveis na internet para auxiliar os professores na elaboração das suas aulas, pois como afirma Moran (2000), o professor tendo uma visão pedagógica inovadora, aberta, que pressupõe a participação dos alunos, pode utilizar algumas ferramentas simples da internet para melhorar a interação entre todos.

O objetivo principal desta pesquisa é analisar as contribuições pedagógicas das mídias, através da análise de um blog, que tem como preocupação alertar para a importância da promoção da saúde no âmbito escolar, orientando para uma vida saudável. Contribuindo com nosso estudo, o Ministério da Saúde compreende que a fase escolar é fundamental para promover saúde, desenvolvendo ações para a prevenção de doenças e para o fortalecimento dos fatores de proteção. Crianças, jovens e adultos que encontram-se nas escolas vivem momentos em que os hábitos e as atitudes estão sendo construídos.

Faggion (2000) ressalta que não basta somente praticar as atividades físicas nas aulas de Educação Física só por praticar, nem tão pouco competir por competir. Segundo ele, é necessário fazer com que os alunos construam conhecimentos que o levem a compreensão de determinada atividade. Sendo assim o aluno poderá entender e vivenciar o seu aprendizado, levando-o, portanto a uma mudança de comportamento e a assumir novas atitudes. Acreditamos, nesse contexto, que é preciso resgatar a importância das aulas de Educação Física no âmbito escolar, para que os nossos alunos compreendam o valor das aulas. Nesse contexto, o professor tem o papel de ser mediador do ensino e da aprendizagem, usufruindo de seus conhecimentos e metodologias adequadas, para trabalhar seus conteúdos atingindo objetivos préestabelecidos, propondo assim a formação integral do aluno. 


\section{Ensino, Saúde e Ambiente - V7 (3), p. 50-69, Dez. 2014}

\section{Um pouco de Revisão da Literatura}

Primeiramente acreditamos ser importante definirmos blog. De acordo com Winer, o primeiro weblog, surgiu no final dos anos 90, construído por Tim Bernes Lee, com o objetivo de apresentar sites que eram dispostos online. Weblog ou blog é uma ferramenta flexível, onde podem ser inseridos posts, com mecanismos simples de fácil criação, edição e manutenção de uma página, e, que pode ser usada a favor da educação, sendo considerada uma potencialidade educativa, pois aumenta a comunicação, encoraja o desenvolvimento do pensamento crítico, oportunizando aos alunos a reflexão, expressão e construção dos saberes. De acordo com Gomes (2005) o blog pode ser dividido sistematicamente em duas categorias de acordo com sua utilização, podendo servir como: recurso pedagógico acessando informações específicas e orientações do professor e, estratégia educativa, sendo utilizado para a construção de portfólio digital e espaço de colaboração, debate, intercâmbio e integração.

Por ser uma ferramenta interativa, os blogs apresentam características técnicas, e a possibilidade de publicação imediata, permitindo postar textos, imagens, músicas, além de hiperlinks que servem para complementar os assuntos em debate e/ou relacionar-se com outros blogs, consideradas ferramentas pedagógicas, apesar de fazerem parte de uma estrutura técnica e não terem sido criadas com este fim.

As possibilidades e vantagens do uso do blog na educação são inovadoras e motivadoras. Pesquisadores têm se preocupado em analisar e descrever as potencialidades de uso dos weblogs na educação. Davis (2013) nos mostra uma relação de atividades a serem desenvolvidas por professores utilizando os blogs. Os alunos podem criar um blog para discutir assuntos, expor suas ideias, escrever e discutir notícias e, criar projetos. Para Barros (2013), os blogs oferecem ótima oportunidade para promover alfabetização através de narrativas e diálogos.

As características dos blogs, como espaço personalizado e os links criam um excelente contexto de comunicação mediada por computador para expressão individual e interações colaborativas no formato de narrativas e diálogos. As autoras Franco e Coutinho (2006) apresentam ainda, características instrutivas de um blog: economia, por serem precisos e específicos na comunicação de ideias; estimula o compartilhamento e a revisão por parte dos leitores e escritores, estabelecendo uma comunicação interativa; o imediatismo, pois tão logo se publica algo em um blog, ele

aparece na rede, o que inicia o sistema de comentários e respostas e ainda, a participação ativa, já que o blog proporciona a oportunidade de discutir temas de sala de 
aula, complementando-os, pensando sobre o assunto, e respondendo, o que induz uma maior participação de todos os estudantes.

Dessa forma, utilizar as mídias tecnológicas atuais nas aulas de Educação Física acaba configurando-se como uma tarefa desafiadora e um pouco difícil, podendo ser considerada complexa, mas que com ações bem planejadas podem trazer inúmeras vantagens. Difícil, pela cultura imposta de que a Educação Física precisa desenvolver corpos sarados e atléticos e, desafiadora, porque irá contribuir na formação crítica do aluno, exigindo mediação e dedicação do professor, que necessita de estudo, empenho, atualização e motivação, como mostram os Parâmetros Curriculares Nacionais (PCN),

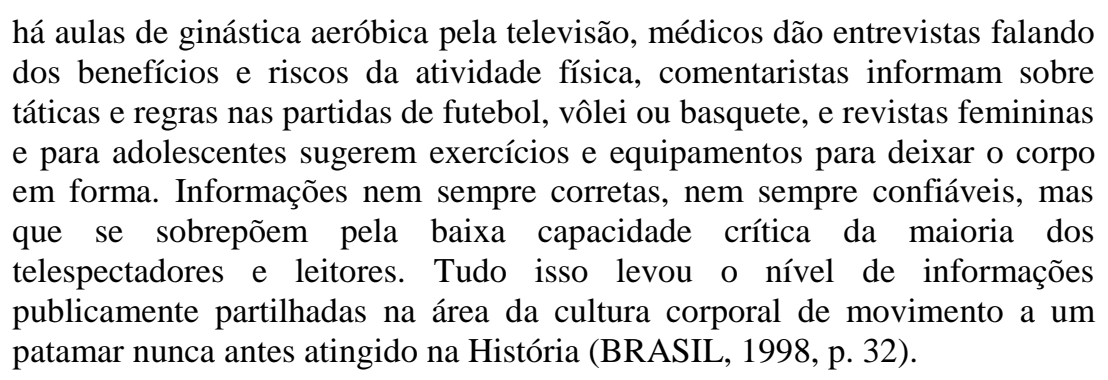

Baseada na afirmação acima, o professor deve exercer o papel de mediador, desenvolvendo nos alunos a capacidade de reflexão/crítica para discernir e absorver informações, repassadas pelas mídias, transformando as mesmas em conhecimento em prol de sua saúde.

Faggion (2000) enfatiza que a Educação Física traz na sua história a valorização das habilidades físicas e morfológicas, técnicas e táticas, constituindo sua identidade nos conhecimentos construídos sobre cultura corporal, jogos, esportes, lutas, ginástica e danças, entre outros. Nos dias atuais a disciplina está muito além, está voltada para questões de saúde, competências e habilidades para adoção de um estilo de vida ativo, e aliar recursos da tecnologia de informação e comunicação, através das ferramentas oferecidas pelas mídias no desenvolvimento de aulas atrativas, inovadoras e interessantes, parece ser uma escolha pertinente.

Segundo Franco (2005) para aprimorar os métodos e estratégias é preciso desenvolver ações pedagógicas com êxito e eficácia de ensino aprendizagem, lançando mão das mídias tecnológicas, podendo utilizar blogs que trabalhem aspectos educacionais, através de ferramentas de interação entre os usuários, que proporcionam debates, discussões e complementação de assuntos e temas educacionais de pesquisa, por meio de postagens e comentários, enriquecendo e dinamizando o trabalho docente. 
Questionamo-nos então: Como um blog pode ajudar no planejamento $e$ desenvolvimento da aula de Educação Física? Verificamos que com o surgimento dos sites de criação, gestão e alojamento de blogs gratuitos e de fácil utilização, a criação de um blog tornou-se uma tarefa acessível e importante para ajudar no desenvolvimento de aulas mais atrativas, evoluindo o ritmo de criatividade e imaginação de alunos e professores, contribuindo para a melhoria e qualidade do ensino (GOMES, 2005). A criação de um blog com objetivos educacionais promove uma maior interação entre professor e aluno, tornando as aulas mais descontraídas, facilitando o desenvolvimento de múltiplas competências e habilidades associadas à pesquisa e ao domínio de ferramentas e serviços da web (BARROS, 2013).

Diante das colocações feitas por tais autores citados, sentimos a necessidade de modificar e atualizar nossas metodologias, para a promoção de estratégias de ensino e de pesquisas baseada e organizada em torno de uma aprendizagem colaborativa que se dará com a utilização das novas mídias tecnológicas, com ênfase no desenvolvimento de competências e habilidades, com objetivo de promover a saúde escolar, pois verificamos a importância de tratar "saúde" com os alunos, nas aulas de Educação Física.

Nesse contexto Brasil (1998, p 36) enfatiza:

As relações que se estabelecem entre o tema transversal Saúde e a Educação Física são quase que imediatas e automáticas ao considerar-se a proximidade dos objetos de conhecimento envolvidos e relevantes em ambas as abordagens. Dessa forma, a preocupação e a responsabilidade na valorização de conhecimentos relativos à construção da autoestima e da identidade pessoal, ao cuidado do corpo, à nutrição, à valorização dos vínculos afetivos e a negociação de atitudes e todas as implicações relativas à saúde da coletividade, são compartilhadas e constituem um campo de interação na atuação escolar.

É neste contexto que a Educação Física exerce um papel significativo na formação dos alunos, através de suas aulas que podem ser tanto teóricas quanto práticas, pois visa a saúde através de uma aprendizagem significativa, trabalhando também as questões competitivas através dos esportes, torneios e campeonatos enfocando questões de humanização e como lidar com vitórias e derrotas.

Acreditamos que a prática de atividades e exercícios físicos é importante para a promoção de saúde das pessoas, e no ambiente escolar, através das aulas de Educação Física, podemos desenvolver aspectos relacionados ao crescimento corporal, inclusão social, desenvolvimento motor, afetividade, sociabilidade, cooperação e aptidões físicas, aliando aos meios de comunicação e interação disponíveis nas mídias. Faggion (2000) 
aponta que o professor é uma ferramenta essencial para desenvolver uma visão crítica, criativa e participativa, pois a partir do momento que o professor adequar conteúdos as faixas etárias, deixando de trabalhar conteúdos com enfoque somente no esporte e competição, permitindo que os alunos compreendam que a Educação Física na escola não se resume apenas ao esporte, desenvolvendo ações pedagógicas e levando a reflexão e compreensão do real valor da disciplina no contexto escolar.

O professor de Educação Física tem a responsabilidade de contribuir para a adoção de um estilo de vida ativo e saudável, garantindo o acesso às práticas da cultura corporal de movimento, promovendo saúde e qualidade de vida, através do trabalho pedagógico realizado na escola. Incentivar a prática regular dos exercícios físicos com autonomia, reforçando a necessidade de prevenção de doenças, tirando o melhor proveito em benefícios para a promoção da saúde. Corrobora com o que estamos propalando, as ideias de Brasil (1998, p. 36):

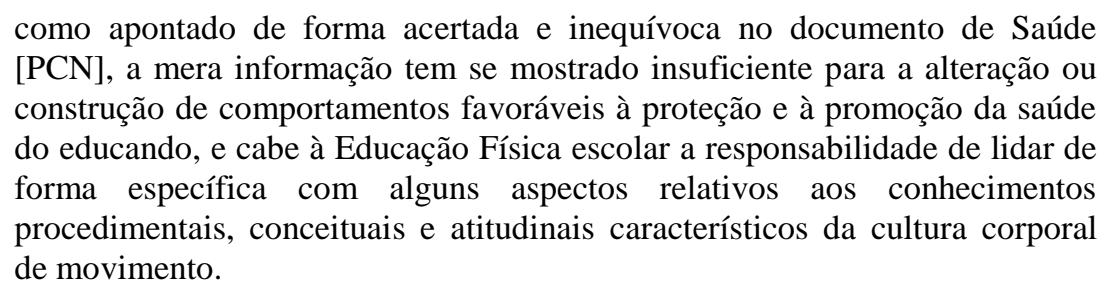

Deste modo, a Educação Física deve contribuir para promover a saúde através da prática de atividades físicas, exercícios e esportes, e, é importante reconhecer que um estilo de vida ativo desempenha um papel crucial para a pessoa se sentir melhor, mais feliz com sua vida.

\section{Metodologia}

A metodologia do estudo configurou-se como de caráter descritivo qualitativo. Procuramos levantar possibilidades de inserção da temática "saúde" nas aulas de Educação Física articulando com a discussão das mídias. A pesquisa qualitativa busca entender os fenômenos específicos em profundidade, trabalhando descrições, interpretações e comparações, sendo mais participativa, direcionando suas interações com o pesquisador, não se atendo a regras, estatísticas e números, convencendo na forma de experimentação empírica. Segundo Minayo (1999), na abordagem qualitativa não podemos querer encontrar a verdade com o que é certo ou errado, preocupando-nos com a compreensão lógica da prática que se dá na realidade. 
A coleta dos dados se deu através de uma pesquisa exploratória inicial em sites e blogs. Para realizar este primeiro levantamento, utilizamos algumas palavras-chave em um portal de busca da internet. As palavras chaves foram: saúde, Educação Física e mídias. Após levantar esse material, realizamos algumas leituras e exploração dos materiais. Concluída essa etapa, optamos por analisar um blog, este serviu para integrar o corpus da pesquisa.

O blog escolhido para análise e problematização durante a pesquisa é denominado "Saúde na escola: promoção da saúde na escola através das aulas de Educação Física"”. Segundo informações disponibilizadas no blog, este "aborda questões de saúde que devem ser tratadas de forma pedagógica através das aulas de Educação Física. Objetivo principal é estimular crianças e jovens para adoção de um estilo de vida ativo, rompendo com o sedentarismo e promovendo melhoria da saúde e qualidade de vida de alunos e alunas". Em virtude do escopo do referido blog, optamos por analisa-lo, visto que ele se propõe a aborda questões de saúde de forma pedagógica nas aulas de Educação Física, indo em direção ao nosso objetivo da pesquisa.

Para a análise do material do blog, foram analisadas todas as postagens disponíveis, desde maio de 2010 até novembro de $2012^{2,3}$. Como ferramenta para essa análise, foi elaborada uma planilha, a qual contemplou os seguintes itens: data e título da postagem; pré-análise; identificação dos recursos disponíveis em cada postagem e; uma análise final, a qual procurou relacionar a postagem com os subsídios que a postagem pode proporcionar ao professor de Educação Física ao elaborar suas aulas que contemplem a discussão da saúde.

\section{Resultado e Discussão}

Os resultados foram analisados por meio da Análise de Conteúdo, a qual para Minayo (2001) possibilita uma aplicação bastante variada, e têm duas funções: verificação de hipóteses e/ou questões e, a descoberta do que está por trás dos conteúdos manifestos. Para Vergara (2005), a Análise de Conteúdo constitui uma técnica que trabalha os dados coletados, objetivando a identificação do que está sendo dito a

\footnotetext{
${ }^{1}$ Blog encontrado no seguinte endereço: <http://saudenaescola.wordpress.com>.

${ }^{2}$ Período em que o blog disponibilizava postagens.

${ }^{3} \mathrm{O}$ material foi analisado de dezembro de 2012 à maio de 2013.
} 
respeito de determinado tema. Partindo dessa técnica, apresentaremos as postagens selecionadas, seguida das análises realizadas no conteúdo destas.

A primeira postagem que apresentamos refere-se à diferenciação entre exercícios aeróbicos e anaeróbicos. A postagem apresenta um volume grande de informações conceituais sobre diferentes tipos de exercícios. Também aborda questões referentes ao gasto calórico, queima de energia, duração dos exercícios e comprometimento muscular. Como recursos, apresenta uma imagem de um quebra cabeça; um texto elaborado a partir de fontes da revista abril e do portal Terra. Nas fontes da postagem existem três links, que favorecem a ampliação na busca de mais informações sobre o assunto, pois segundo Palacios e Mielniczuk (2001), o link é um elemento realmente inovador apresentado pelo hipertexto em suporte digital, sendo um recurso técnico para potencializar características de intertextualidade e multimidialidade.

Analisamos que a postagem apresenta a diferença entre exercícios aeróbicos e anaeróbicos, contribuindo para a execução dos exercícios físicos durantes as aulas e chamando a atenção para a importância e necessidade de ambos os tipos. A postagem traz exemplos de atividades físicas que se enquadram nos diferentes modelos e características que contribuem para a saúde e desenvolvimento de aulas teóricas e práticas na disciplina de Educação Física. Com estes pressupostos, as aulas podem ser desenvolvidas em forma de oficinas, sistematizando conhecimentos novos aliados a conhecimentos já assimilados pelo aluno.

A segunda postagem analisada é "Energia para o exercício Físico". O conteúdo desta explica a proveniência e uso de energia em diferentes tipos de exercícios físicos, entrando na área da Biologia, detalhando os tipos de reações químicas, durações e denominações. Traz a imagem do ATP, demonstrando e exemplificando o conteúdo abordado. As tarefas são pertinentes, podendo servir de referencial para avaliar e diagnosticar os alunos, promovendo saúde nas aulas de Educação Física.

A postagem "Você sabe o que é atividade física, exercício físico e aptidão física?", traz as seguintes definições:

Atividade física: A atividade física nada mais é do que a simples realização de um movimento. Está sempre presente no nosso dia-a-dia quando fazemos o mínimo de esforço para caminhar, tomar banho, levantar de algum lugar, vestir alguma roupa e, porque não, escovar os dentes, por exemplo.

Exercício físico: É uma atividade repetitiva, planejada e estruturada, que tem como objetivo a manutenção e melhoria de um ou mais componentes da aptidão física, com horário e compromisso marcado. 
A Aptidão Física seria uma série de atributos adquiridos em função da prática regular da atividade física. Qualidades físicas desenvolvidas: força, flexibilidade resistência aeróbica, anaeróbica, coordenação motora.

Tarefas:

1) Descreva as atividades físicas a que você desenvolve no seu dia-a-dia?

2) Cite, se for o caso, se realiza exercício físico e, qual seu objetivo?

3)Quais as aptidões físicas adquiridas com a prática regular e contínua do exercício físico?

Postagem 3: Você sabe o que é atividade física, exercício físico e aptidão física?

Publicada em: 15 maio 2010

A postagem é interessante, simples, clara e de fácil compreensão. Configura-se como importante para diferenciar, complementar e entender os diferentes tipos de exercícios. A postagem analisada traz informações que trabalhadas com os alunos permitem clarear as diferenças entre exercício e atividade física, bem como salientar a importância e presença de ambos na promoção de saúde. Pelos atributos do conteúdo ser relevante para a vida dos alunos é importante que o professor torne tais conhecimentos tão populares quanto os jogos, a dança e a ginástica.

A postagem 4 (Figura 1) é interessante por trazer: dicas importantes, frases que alertam para a saúde, o funcionamento do coração e o nível do fluxo sanguíneo nas veias e artérias. A mesma traz também, um vídeo que mostra o funcionamento do coração, da corrente sanguínea e demais sistemas como o respiratório e o muscular. Segundo Moran, através dos vídeos os alunos compreendem melhor, se interessam mais e as aulas se tornam mais atraentes dinâmicas e participativas estimulando a criatividade, comunicação audiovisual e interação, além disso, os vídeos dirigem-se antes a afetividade do que a razão, desenvolvendo a sensibilidade. A postagem encoraja, anima e incentiva a prática saudável, mostrando os mecanismos de prevenção de doenças, que podem colaborar muito na elaboração e execução das aulas de Educação Física, bem como a globalização do conteúdo com outras áreas de estudo, promovendo saúde na escola. Através de uma educação com autonomia, contribui para os alunos praticarem, também, atividades físicas fora do âmbito escolar, pois dois períodos semanais não são suficientes para que ocorram mudanças fisiológicas em benefício da aptidão física. 
Figura 1: Postagem 4 - Sistema Cardiovascular dicas para uma vida saudável, postado em 22 jun. 2010

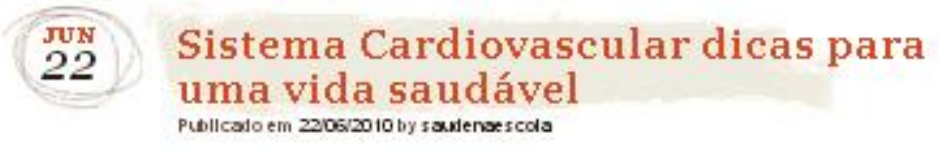

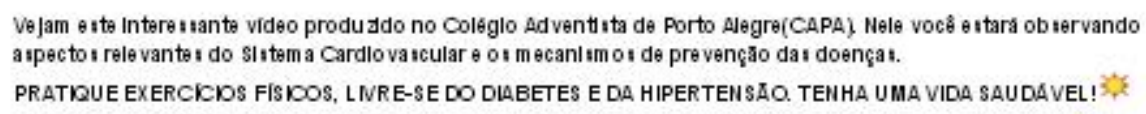

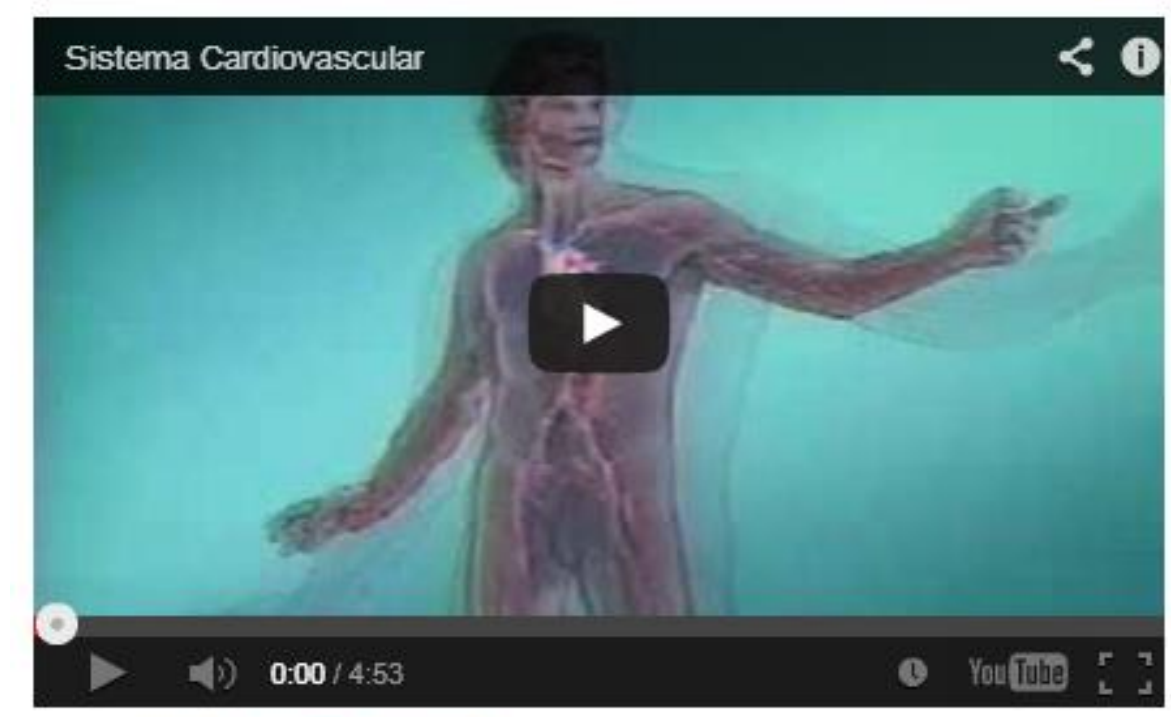

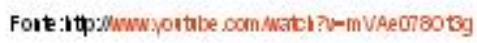

Fonte: http://saudenaescola.wordpress.com/2010/06/

Vejamos a postagem 5, "Você é uma pessoa sedentária?":

O sedentarismo já é considerado a doença do próximo milênio. Na verdade trata-se de um comportamento induzido por hábitos decorrentes dos confortos da vida moderna. Com a evolução da tecnologia e a tendência cada vez maior de substituição das atividades ocupacionais que demandam gasto energético por facilidades automatizadas, o ser humano adota cada vez mais a lei do menor esforço reduzindo assim o consumo energético de seu corpo.

O que é o sedentarismo? O sedentarismo é definido como a falta ou a grande diminuição da atividade física. Na realidade, o conceito não é associado necessariamente à falta de uma atividade esportiva. Do ponto de vista da Medicina Moderna, o sedentário é o indivíduo que gasta poucas calorias por semana com atividades ocupacionais. Segundo um trabalho realizado com ex-alunos da Universidade de Harvard, o gasto calórico semanal define se o indivíduo é sedentário ou ativo. Para deixar de fazer parte do grupo dos sedentários o indivíduo precisa gastar no mínimo 2.200 calorias por semana em atividades físicas.

Quais são as consequências do sedentarismo? A vida sedentária provoca literalmente o desuso dos sistemas funcionais. $\mathrm{O}$ aparelho locomotor e os demais órgãos e sistemas solicitados durante as diferentes formas de atividade física entram em um processo de regressão funcional, caracterizando, no caso dos músculos esqueléticos, um fenômeno associado à atrofia das fibras musculares, à perda da flexibilidade articular, além do comprometimento funcional de vários órgãos.

Quais as doenças associadas à vida sedentária? O sedentarismo é a principal causa do aumento da incidência de várias doenças. Hipertensão arterial, diabetes, obesidade, ansiedade, 
aumento do colesterol, infarto do miocárdio são alguns dos exemplos das doenças às quais o indivíduo sedentário se expõe. O sedentarismo é considerado o principal fator de risco para a morte súbita, estando na maioria das vezes associado direta ou indiretamente às causas ou ao agravamento da grande maioria das doenças.

\section{Postagem 5: Você é uma pessoa sedentária?}

Publicada em: 28 jun. 2010

A postagem usa o blog para expor a problemática que envolve sedentarismo e promoção de saúde. Traz definições, consequências e doenças associadas à diminuição ou falta de atividade física. Apresenta um vídeo com as modernidades tecnológicas, academias e diferentes tipos de exercícios que podemos substituir no nosso dia a dia para tornar nossa vida mais saudável. Acreditamos ser possível aliar o conteúdo da postagem as aulas de Educação Física com o objetivo de diminuir o número de pessoas sedentárias e alertar para os riscos e consequências do sedentarismo, refletindo dobre uma nova proposta de desenvolver conteúdos específicos e relacionados a atividade física e promoção de saúde no âmbito escolar.

A postagem 6, "Promoção da Saúde começa na Escola!" (publicada em 07 jul. 2010), traz dados de pesquisa realizadas em 2006, 2007 e 2008 em diferentes capitais e sexos, para determinar variações no percentual de indivíduos expostos a fatores de risco e indivíduos fisicamente inativos, determinando índices e níveis de sedentarismo (Tabela 1).

Tabela 1: Sedentarismo - Percentual de indivíduos fisicamente inativos por sexo, segundo idade

\begin{tabular}{|l|c|c|c|}
\hline Variáveis & Total & Masculino & Feminino \\
\hline \multicolumn{1}{|c|}{ Idade (anos) } & $\%$ & $\%$ \\
\hline 18 a 24 & 26,2 & 26,0 & 26,3 \\
\hline 25 a 34 & 21,4 & 26,7 & 16,6 \\
\hline 35 a 44 & 21,7 & 28,1 & 16,2 \\
\hline 45 a 54 & 24,3 & 29,8 & 19,5 \\
\hline 55 a 64 & 31,8 & 34,1 & 30,0 \\
\hline 65 e mais & 52,6 & 51,7 & 53,2 \\
\hline
\end{tabular}

Fonte: http://saudenaescola.wordpress.com/2010/07/

A postagem apresenta também um vídeo para reflexão. A partir do estudo e reflexão crítica da postagem, confrontando conhecimentos já assimilados a novas perspectivas pode-se realizar um trabalho pedagógico nas aulas de Educação Física, estimulando a adoção de um estilo de vida ativo, com autonomia, promovendo a saúde e qualidade de vida, reafirmando palavras da postagem. Acreditamos que o investimento 
Ensino, Saúde e Ambiente - V7 (3), p. 50-69, Dez. 2014

em prevenção é necessário e estimulado na escola pode trazer futuros benefícios para a saúde.

Vejamos a postagem 7 “Autonomia para realização do exercício físico” (postada em 10 jul. 2010):

Figura 3: Parte da postagem 7 - Autonomia para realização do exercício físico
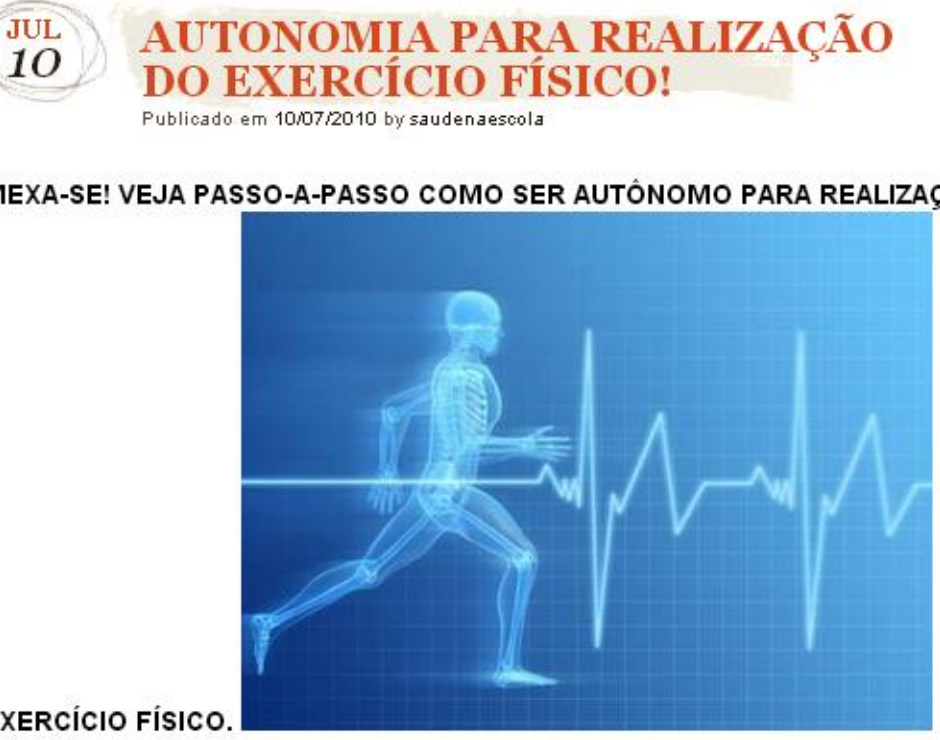

Fonte: http://saudenaescola.wordpress.com/2010/07/

$1^{\circ}$ : PASSO: Saber o que é frequência cardíaca, frequência cardíaca máxima e o método de zona alvo para realização do exercício físico.

a) Frequência cardíaca: É o número de vezes que o coração bate por minuto (bpm).

b) Frequência cardíaca máxima: É o número de batimentos cardíacos que devem ser observados na realização do exercício físico, em função, principalmente, de sua idade. É a margem de segurança para realização do esforço.

c) Método de zona alvo: Calculado a partir de sua frequência cardíaca máxima, especificando a faixa ideal de esforço que um indivíduo deve realizar, expresso pelos limites superior e inferior. Deve observar também o grupo no qual está inserido.

20PASSO: Verificar a frequência cardíaca. Como disse, é expressa em batimentos por minuto. Para isso, use um relógio de pulso com marcação de segundos e, com os dedos indicador e médio pressione as artérias carótida (pescoço) ou artéria radial (punho). Outro ponto, pode ser o ápice do coração. Conte 15 segundos e multiplique por 4. Assim, teremos a frequência cardíaca por minuto em repouso ou esforço. Veja as fotos 


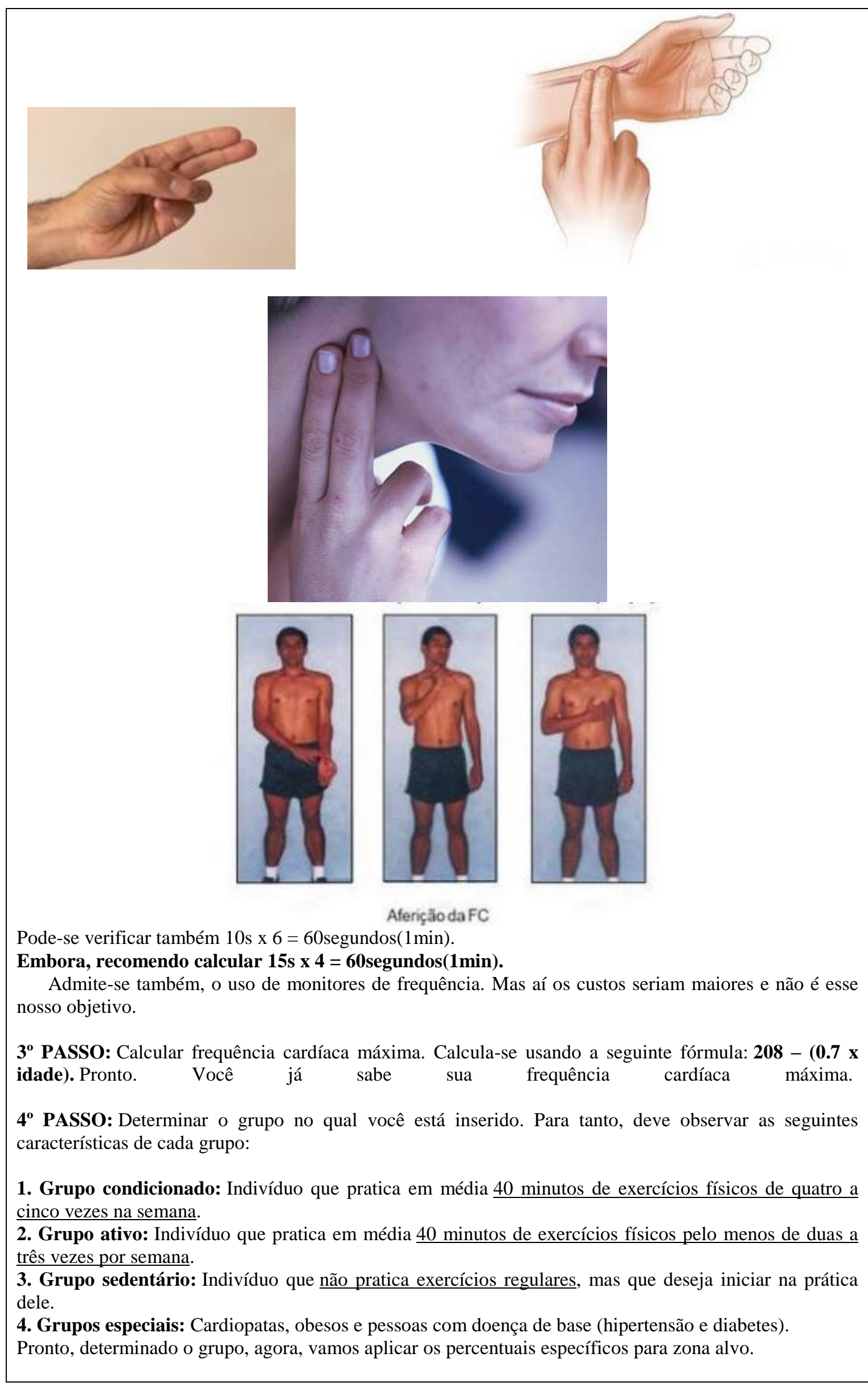


$5^{\circ}$ PASSO: Determinar a zona alvo para realização do trabalho físico. Lembrar que você já determinou sua frequência cardíaca máxima (fcmáx). Assim, deve aplicar os seguintes percentuais para cada grupo:

1. Grupo condicionado: Aplica-se: Limite superior: fcmáx x 95\%. Limite inferior: fcmáx x $85 \%$.

2. Grupo ativo: Aplica-se: Limite superior: fcmáx x 85\%. Limite inferior: fcmáx x $75 \%$.

3. Grupo sedentário: Aplica-se: Limite superior: fcmáx x 75\%. Limite inferior: fcmáx x 65\%.

4. Grupos especiais: Devem sempre procurar ajuda clínica. Entretanto, podem aplicar percentuais específicos em torno de $65 \%$ para limite superior $55 \%$ para limite inferior.

Veja o exemplo abaixo: Pessoa 30 anos inserida no grupo condicionado. Lembrar da fórmula fcmáx: 208 - (07 $\mathrm{X}$ idade).

Cálculo Fc máx: 208 - 0.7 x 30(idade)= FC MÁX. 187bpm

LSUPERIOR= fcmáx(187) X 95\%= LIMITE SUPERIOR: 178 bpm

LINFERIOR= fcmáx(187) X 85\% = LIMITE INFERIOR: 159 bpm

ESSA É A ZONA ALVO! O esforço deve ser estabelecido nesta faixa que vai de 159bpm até $178 \mathrm{bpm}$ para qualquer atividade que venha realizar.

Lembrando que o resultado acima segue o exemplo citado! Faça os cálculos em função de sua faixa de idade e o grupo no qual está inserido:condicionado, ativo, sedentário e especiais. Não se esquecendo da fórmula para cálculo da frequência cardíaca máxima:Fc máx: 208 - (0.7 x idade)

$6^{\circ}$ PASSO: Pegue um tênis, uma roupa confortável e vamos pra rua! Mexa-se!!!!!

Abaixo relaciono o vídeo produzido do CENTRO DE ENSINO MÉDIO BOM JESUS. Turma 123. Bom trabalho que relaciona valores do exercício físico para saúde. Vejam! Aproveitando para parabenizar os alunos deste Colégio pelo trabalho realizado. Assim é o trabalho colaborativo.

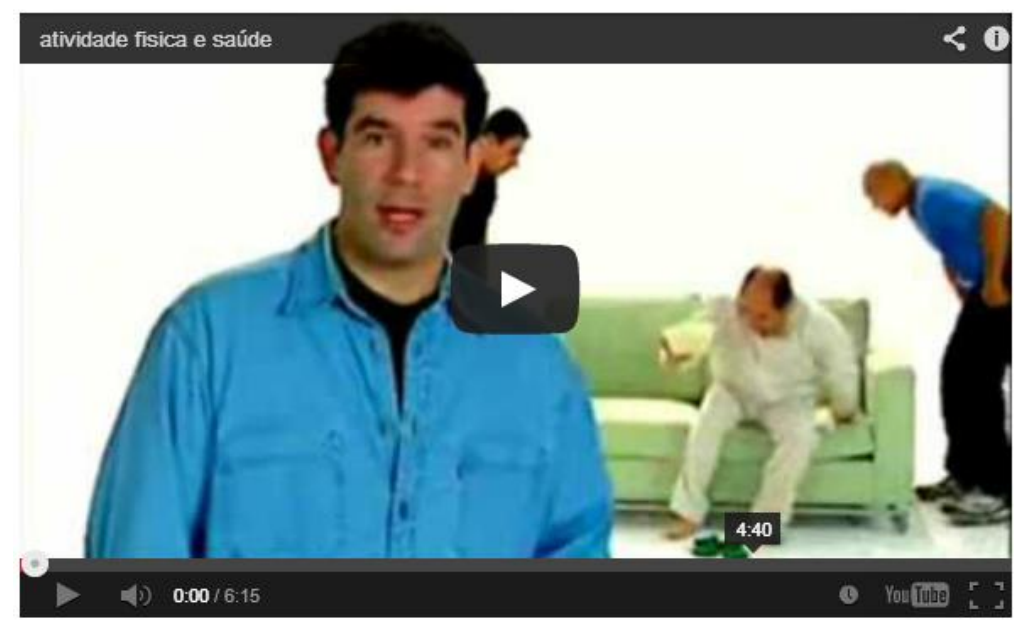

Fonte:http://www.youtube.com/watch?V=IAfliHCV_k\&feature=related

Postagem 7: Autonomia para realização do exercício físico Publicada em: 10 jul. 2010

Analisando essa postagem, acreditamos que podemos utilizar seu conteúdo para ensinamos os alunos a aferir a frequência cardíaca e, a desenvolver autonomia para a realização de atividades físicas saudáveis, aproveitando o texto explicativo, vídeo e fotos ilustrativas. Acreditamos que realizando os cálculos e aferições ensinados, para identificar os exercícios adequados para cada um, os alunos podem obter autonomia para realização de exercícios físicos saudáveis. Desta maneira estaremos propiciando 
Ensino, Saúde e Ambiente - V7 (3), p. 50-69, Dez. 2014

uma educação de qualidade, atingindo objetivos e parâmetros de saúde nas aulas de Educação Física.

A postagem 8, "O crescente arredondamento das formas" (postada em 20 mar.

2011), consiste em um texto escrito pelo Biólogo Bruno Francheschi Troiano, o qual apresentamos abaixo:

No Brasil, a obesidade já é considerada um sério problema de saúde pública. Segundo dados do Ministério da Saúde, 3,5 milhões de brasileiros estão em estado de obesidade mórbida - quando o peso de uma pessoa ultrapassa o valor 40 no índice de massa corporal (IMC, divisão do peso pela altura). Segundo uma pesquisa do Instituto Brasileiro de Geografia e Estatística (IBGE), de 2004, cerca de 10\% das crianças e adolescentes brasileiros estão acima do peso e a cada ano esse número aumenta. A obesidade infantil provoca problemas precoces como hipertensão, colesterol elevado, diabetes, doenças ortopédicas e até mesmo bullying nas escolas. Crianças diagnosticadas com obesidade desenvolvem hábitos como insaciabilidade - algumas chegam a repetir o prato até três vezes, durante as refeições - têm muita sede e cansaço exagerado.

Uma das razões que contribuem para esse quadro é a junk food - alimentos altamente calóricos, mas pouco nutritivos. Hambúrgueres gordurosos, batatas fritas, milk-shake, sorvetes, pizzas, de fácil acesso às crianças, podem ser considerados atentados à saúde infantil. A publicidade massiva em torno desses alimentos, no entanto, faz com que sejam consumidos de maneira crescente.

$\mathrm{Na}$ verdade, a junk food não é prejudicial apenas a crianças e adolescentes. Como resultado do consumo crescente, as estatísticas mostram que adultos brasileiros também arredondam perigosamente suas formas, com impacto direto na qualidade da saúde. $\mathrm{O}$ aumento do poder aquisitivo, mais recentemente, fez crescer o consumo desses alimentos - não apenas em restaurantes do tipo fast-food. No Brasil, cresce também o consumo de comidas congeladas com elevadas concentrações de conservantes, como reflexo de mudanças na estrutura social.

Segundo o mesmo estudo do IBGE, por volta de $43 \%$ dos brasileiros estão acima do peso ideal e $13 \%$ são obesos - porcentagem já elevada, mas equivalente a pouco mais que um terço da população americana de obesos.

O quadro de obesidade mórbida está associado, quase sempre, a uma diversidade de causas. Entre elas, fatores biológicos e ambientais. Os fatores biológicos envolvem genética e metabolismo, enquanto depressão, angústia e ansiedade são considerados fatores ambientais.

Há casos em que mesmo dietas e exercícios físicos não resultam em perda de peso, ao contrário. A pessoa pode ganhar ainda mais massa corpórea. As dietas radicais - normalmente divulgadas por revistas populares - não necessariamente funcionam, pois ao final de um ciclo a pessoa sente mais fome que normalmente, devido à falta de nutrientes ingeridos. Daí a importância de um tratamento criado e acompanhado por um profissional especializado na área. No Brasil, o tratamento contra a obesidade, na melhor das hipóteses, é acompanhado por nutricionistas. No entanto, praticamente não existe apoio com base nas ciências do comportamento, levando em conta que boa parte das dificuldades dos obesos é também de natureza psicológica.

Uma opção para obesos ou pessoas acima do peso ideal interessadas em emagrecer de maneira saudável é o Vigilantes do Peso (www.vigilantesdopeso.com.br), organização mundial que participa ativamente do fórum científico global de disciplinas relacionadas ao controle do peso, dando suporte e acompanhamento para interessados. Na cidade de São Paulo, pacientes com quadro de obesidade mórbida podem recorrer ao tratamento no Hospital das Clínicas da FMUSP. No ano passado, o hospital iniciou testes com um novo tratamento que consiste em inserir uma prótese endoscópica flexível - com $62 \mathrm{~cm}$ de comprimento - na porção inicial do intestino delgado. Os primeiros resultados revelam perda de aproximadamente $30 \%$ de peso, o que correspondeu ao esperado pelos pesquisadores. Mas esta ainda está longe de ser uma solução ideal. 


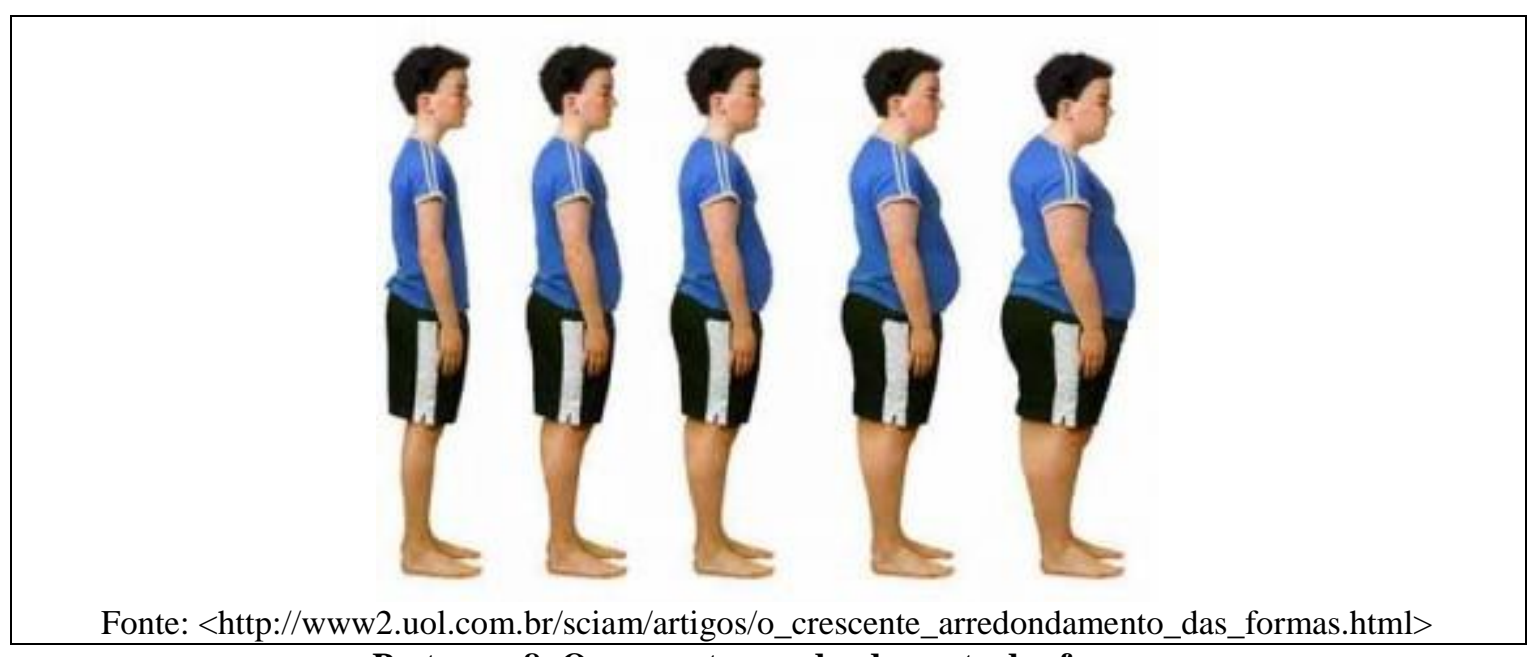

Postagem 8: 0 crescente arredondamento das formas

Publicada em: 20 mar. 2011

A postagem 8 chama nossa atenção para casos de obesidade e problemas de sobrepeso, por maus hábitos alimentares, falta de atividade física e doenças associadas a fatores biológicos e ambientais. Acreditamos que essa postagem, se for trabalhada e desenvolvida nas aulas de Educação Física, levando em conta principalmente os fatores biológicos (genética e metabolismo) e ambientais (depressão, angustia e ansiedade), podem contribuir para um melhor estilo de vida dos alunos.

Podemos começar apresentando o texto da postagem, discutindo a atividade física conceitualmente e o que ela representa para a sociedade, depois ampliar falando de saúde, mostrando seus conceitos e qual a origem destes para que se tenha um entendimento social sobre o fenômeno. Ao final podemos ampliar um pouco mais este leque de referencias e mostrar os tipos de atividade física, alterações fisiológicas, benefícios e malefícios provocados pela atividade física.

A próxima postagem que destacamos é: “Atividades da Vida Diária: Atividade Física Incidental" (publicada em 17 maio 2011). A postagem apresenta uma matéria publicada no jornal O Globo. Afirma que movimentos cotidianos, como varrer a casa, dar banho em crianças, subir escadas e outros contribuem para o preparo físico e que essas atividades consideradas incidentais caíram muito nos dias atuais. Baseados nessa afirmativa, podemos incentivar nossos alunos a praticar atividades incidentais, como vir para escola caminhando ou de bicicleta e ajudar os pais nas tarefas diárias, levando em conta que tais atividades são capazes de produzir efeitos positivos e contribuir para o desenvolvimento físico, em nossas aulas, incentivando e promovendo maior qualidade de vida e a promoção de saúde. 
A postagem 10 - "Sedentarismo" traz definições, orientações, consequências, recomendações, alternativas e indicações de exercícios, que farão com que seu leitor dê uma atenção especial a problemática do sedentarismo. Reforça aspectos importantes sobre saúde e qualidade de vida, prevenindo uma série de doenças associadas ao sedentarismo. Este tema consegue abranger vários aspectos para serem debatidos, estudados e refletidos nas aulas de Educação Física, pois na escola podemos fazer este link entre saúde e educação. Através de atividades pedagógicas, teóricas, virtuais e práticas que conseguiremos alcançar nosso objetivo maior que é a promoção de saúde na escola.

A postagem 11, "Efeitos colaterais do uso dos anabolizantes", publicada em 06 jun. 2012 trata de um assunto importantíssimo, principalmente de ser discutido entre jovens, que desejam corpos perfeitos e, para isso, por vezes, fazem uso de anabolizantes. A postagem possibilita que os professores, alertem para os riscos e efeitos colaterais do uso de tal substância, exemplificado com o vídeo. A partir da postagem pode-se criar discussões, debates e alternativas, com enfoque pedagógico, para o uso de anabolizantes, alertando para os perigos e objetivando uma vida mais saudável.

A última postagem que escolhemos para apresentar nesse trabalho é "Aprendizado baseado em projetos: Uma tendência para Educação Física na web 3.0", publicada em 10 out. 2012 (Figura 8). Analisamos que essa, traz questões pedagógicas importantes que auxiliam no desenvolvimento de projetos com autonomia e gestão de conteúdos pelo professor de Educação Física. Mostra que através das tecnologias, os padrões de comportamento da sociedade foram alterados, facilitando a busca pelo conhecimento, no qual os alunos se tornam produtores deste. Reforça questões de saúde e qualidade de vida, lançando mão de ferramentas como o blog, as redes sociais, o youtube e outras. 
Figura 8: Parte da postagem “Aprendizado baseado em projetos: Uma tendência para Educação Física na web 3.0"

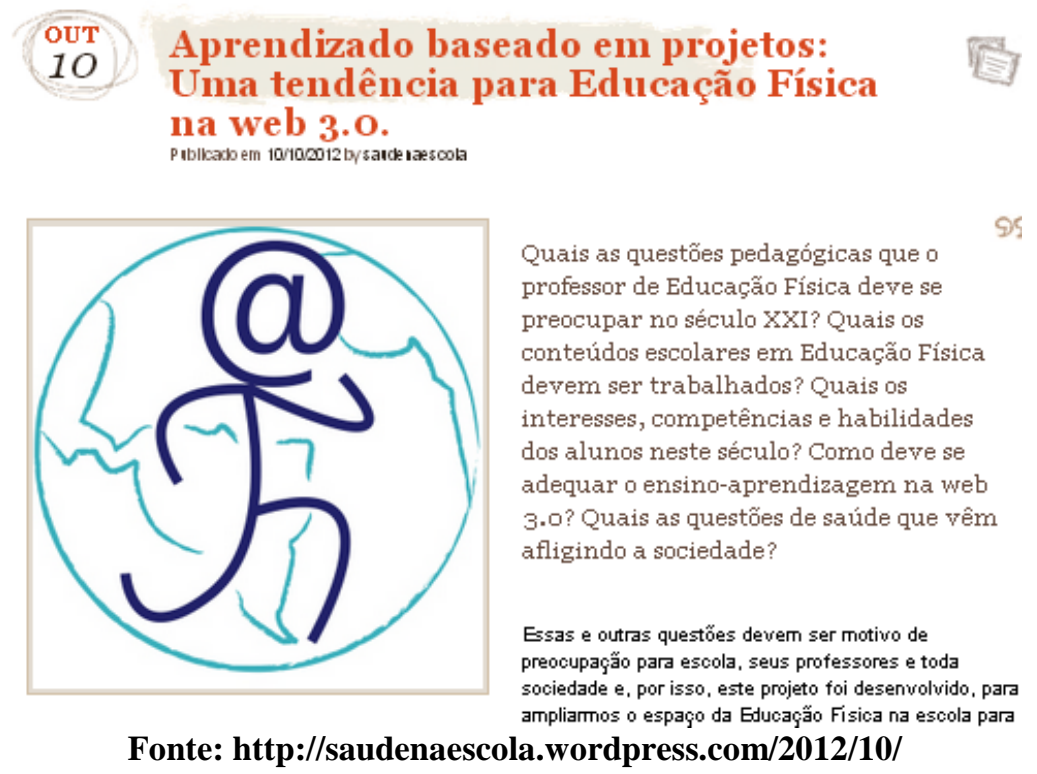

\section{Considerações finais}

A partir das análises realizadas sobre as postagens do blog, que contribui para a promoção da saúde nas aulas de Educação Física, compreendemos que esta ferramenta educacional cooperativa, pode servir de apoio para elaboração de aulas mais interativas e dinâmicas. Para Darido et al. (2010) o blog apresenta-se como um material didático virtual, configurando-se como um recurso que pode auxiliar os professores na tarefa de ensinar.

Além de constituir-se como um espaço pedagógico, o blog permite a construção interativa de novos conhecimentos, compartilhamento de ideias e, a análise crítica do conteúdo das postagens. Através de vídeos, textos, pesquisas, fotos, definições, doenças associadas e suas consequências, bem como alternativas para os problemas enfrentados, o blog analisado possibilita um enriquecimento a prática educativa do professor de Educação Física.

Entendemos que o blog apresenta uma grande contribuição para a promoção de saúde nas aulas de Educação Física, visto que, apresenta assuntos atuais, importantes e de interesse dos alunos. Desta forma servindo de modelo para elaboração de aulas, que possam garantir um aprendizado interativo e motivador. Para Freire (1996), ninguém ensina ninguém; tampouco ninguém aprende sozinho. Os homens aprendem em comunhão, por isso as mídias se tornam um aliado no processo de ensino e possibilita entender a importância e eficiência do blog do ponto de vista da construção do 
conhecimento na relação aluno-pensamento, que vai além da relação entre professor e aluno. Os blogs, com publicações dinâmicas e postagens atuais facilitam a docência e o aprendizado dos alunos, pois a partir deles podemos fazer constatações, complementações, mudanças, críticas com o objetivo de enriquecer o trabalho pedagógico, promovendo saúde e salientando a importância das atividades físicas saudáveis.

\section{Referências}

BARROS, M. A. Ferramentas informacionais para educação e alfabetização: considerações acerca do uso dos blogs como tecnologia educacional. Disponível em: <http://www.rabci.org/rabci/sites/default/files/blogs.pdf>. Acessado em março de 2013.

BRASIL. Secretaria de Educação Fundamental. Parâmetros Curriculares Nacionais: terceiro e quarto ciclos - apresentação dos temas transversais. Brasília: MEC/SEF, 1998.

COUTINHO, C. Utilização de blogues na formação inicial de professores: um estudo exploratório. In: PANIZO et al (Orgs.). Proceedings of the 8th International Symposium on Computers in Education, v. 2, p. 157-164, 2006. Disponível em:

<http://repositorium.sdum.uminho.pt/bitstream/1822/6455/1/Artigo\%20blogs\%20SIIE0 6.pdf $>$. Acessado em março de 2013.

DARIDO, S. C. et al. Livro didático na educação física escolar: considerações iniciais. Motriz, v. 16, n. 2, p. 450-457, 2010.

DAVIS, A. What are the possibilities for weblogs in education? Disponível em: <http://itc.blogs.com/necc2004/2004/05/what_are_the_po.html>. Acessado em março de 2013.

FAGGION, C. A. A prática docente dos professores de educação física do ensino médio das escolas públicas de Caxias do Sul. (Dissertação de Mestrado). Escola de Educação Física da Universidade Federal do Rio Grande do Sul - UFRGS. Porto Alegre: 2000.

FRANCO, M. Blog Educacional: ambiente de interação e escrita colaborativa. Anais XVI Simpósio Brasileiro de Informática na Educação - SBIE. UFJF. Minas Gerais: 2005. Disponível em:

<http://ceie-sbc.educacao.ws/pub/index.php/sbie/article/view/416/402>. Acessado em março de 2013.

FREIRE, P. Pedagogia da Autonomia: saberes necessários à prática educativa. São Paulo: Paz e Terra, 1996.

GOMES, M. J. Blogs: um recurso e uma estratégia pedagógica. In: MENDES, A.; PEREIRA, I.; COSTA, R. (Orgs.). Actas do VII Simpósio Internacional de Informática Educativa. Leiria: Escola Superior de Educação de Leiria. p. 311-315, 2005. 
Ensino, Saúde e Ambiente - V7 (3), p. 50-69, Dez. 2014

MINAYO, M. C. S. O desafio do conhecimento: pesquisa qualitativa em saúde. 6 ed. São Paulo: Hucitec, , 1999.

MINAYO, M. C. S. Pesquisa social: teoria, método e criatividade. Rio de Janeiro, 2001.

MORAN, J. M. C. Mudar a forma de ensinar e de aprender com tecnologias. Interações (Universidade São Marcos), São Paulo, v. 5, n. 9, p. 57-72, 2000.

PALACIOS, M.; MIELNICZUK, L. Considerações para um estudo sobre o formato da notícia na Web: o link como elemento paratextual. In: Anais do XI Congresso da Compós. Brasília, 2001.

VERGARA, S. C. Método de pesquisa em administração. São Paulo: Atlas, 2005.

WINER, D. The history of weblogs. Disponível em:

<http://oldweblogscomblog.scripting.com/historyOfWeblogs>. Acessado em março de 2013. 